\title{
Downregulation of activin-signaling gene expression in passaged normal human dermal fibroblasts
}

\author{
YOUNG IL KIM ${ }^{1}$, CHAN-YANG LEE ${ }^{2}$ and MIN KYUNG SHIN ${ }^{2}$ \\ ${ }^{1}$ Medical Science Research Institute, Kyung Hee University Medical Center; \\ ${ }^{2}$ Department of Dermatology, College of Medicine, Kyung Hee University, Seoul 02447, Republic of Korea
}

Received June 20, 2019; Accepted November 5, 2019

DOI: $10.3892 /$ br.2019.1258

\begin{abstract}
Activins are members of the transforming growth factor- $\beta$ (TGF- $\beta$ ) superfamily and play important roles in proliferation, differentiation, and apoptosis of various target cells. We investigated changes of activin, activin receptor (ActR), and Smad-signaling gene expression with increasing passage number in normal human dermal fibroblasts. The expression of mRNA and protein was measured by reverse transcription-quantitative polymerase chain reaction and immunoblot analysis from passage numbers 5 to 15 . Activin A and follistatin transcript levels increased with increasing passage number. ActR types IA, IB, IIA and IIB mRNA levels decreased at high passage number. The levels of $\operatorname{Smad} 2,3$ and 4 protein decreased with increasing passage number, which also attenuated phosphorylation of Smad 2 and 3 protein expression. Smad7 was enhanced with increasing passage number. These results suggest that expression of activin-signaling in aging normal human dermal fibroblasts increases activin A and follistatin, whereas ActR-Smad signaling is decreased.
\end{abstract}

\section{Introduction}

Activins are members of the transforming growth factor- $\beta$ (TGF- $\beta$ ) superfamily and are growth and differentiation factors that exert effects on a broad range of cells and tissues $(1,2)$. Activin signaling plays a role in regulating the normal proliferation and differentiation in epidermal keratinocytes. A previous study summarized activin signaling transduction and interaction between activin and TGF- $\beta$ signaling during hair follicle formation, hair growth cycling, skin function, and wound healing (3). Follistatin is an activin-binding protein that functions as an antagonist by binding TGF- $\beta$ family members such as activin, bone morphogenetic proteins, myostatin, growth differentiation factor 11 , and TGF- $\beta 1$

Correspondence to: Professor Min Kyung Shin, Department of Dermatology, College of Medicine, Kyung Hee University, 23 Kyung Hee Dae-ro, Dongdaemun-gu, Seoul 02447, Republic of Korea E-mail: haddal@hanmail.net

Key words: activin, activin receptor, fibroblast, follistatin, Smad to block interaction with their signaling receptors. Activin and follistatin play important roles in skin development, inflammatory processes, angiogenesis, and wound healing. There is information about the expression of activin subunits and receptors in fibroblasts and keratinocytes, but there is no report of regulation of follistatin expression in these cells (4).

The biological activity of activin is regulated by specific heteromeric complexes consisting of type I and type II serine/threonine kinase receptors. Activin receptor (ActR) type II binds activin independently of ActR I are unable to signal without ActR I. Formation of heteromeric complexes of ActR I and ActR II is required for mediation of cellular signals (5). The signal transduction pathway is conserved for the TGF- $\beta$ superfamily members, involving the receptor-Smad system. Smad is a primary mediator of TGF- $\beta$ signaling. Smad 2 and Smad3 heterodimerize with Smad4 and translocate to the nucleus to participate in transcriptional regulation of target genes (6). Smad7 functions as an inhibitor of TGF- $\beta$ signaling, including activin signaling (7). Transcription of SMAD7 is induced by TGF- $\beta$ or activin, which indicates the negative feedback mechanism of TGF- $\beta$ /activin signaling (8). The role of the activin/Smad pathway in regulating in vitro-aged normal fibroblasts remains unclear. Previous studies have shown that number of normal human dermal fibroblast gradually reduced with increasing passage number, and expression of aging biomarkers, including procollagen type I and VII, elastin, fibrillin-1, and SIRT1 and SIRT6 were downregulated by passaging (9).

We investigated changes of activin, its receptors, and Smad-signaling gene expression with increasing passage number in normal human dermal fibroblasts.

\section{Materials and methods}

Culture of normal human dermal fibroblasts. Normal human dermal fibroblasts were isolated from tissue removed after circumcision of two 13- and 14-year-old males. The procedures followed in the present study were approved by the Institutional Review Board Committee of the Kyung Hee University Medical Center (Seoul, Republic of Korea; KMC IRB no. 0407-01), and adhered to the recommendations of The Declaration of Helsinki. The human dermal fibroblasts were cultured in Dulbecco's modified Eagle's medium containing $10 \%$ fetal bovine serum and antibiotics (Gibco; Thermo Fisher 
Scientific, Inc.) at $37^{\circ} \mathrm{C}$ in a humidified atmosphere of $5 \% \mathrm{CO}_{2}$ and $95 \%$ air. Previously, our group characterized the isolated fibroblasts of different passages for their proliferative capacity, and the results demonstrated that their population doubling time was significantly increased with passage number (9), confirming that the proliferative capacity of the fibroblasts gradually declined with serial passaging. The cell population doubling time was calibrated by a formula of Kuchler (10).

$R N A$ extraction and reverse transcription-quantitative polymerase chain reaction $(R T-q P C R)$. Total RNA was purified from cultured cells using the TRIzol reagent method and following the manufacturer's protocol (Invitrogen; Thermo Fisher Scientific, Inc.). First-strand cDNA synthesis was performed with $1 \mu \mathrm{g}$ of total RNA and Oligo(dT) $)_{15}$ primers using a reverse transcription system (Promega Corporation), according to the manufacturer's protocol. The primer sequences and product size were as follows: activin A (5'-GGACATCGGCTGGAATGACT-3' and 5'-GGCACT CACCCTCGCAGTAG-3', 71 bp), follistatin (5'-CAGTAAGTC GGATGAGCCTGTCT-3' and 5'-CAGCTTCCTTCATGG CACACT-3', 74 bp), ActR IA (5'-AGGCTGCTTCCAGGT TTATGAG-3' and 5'-TGGCAGCACTCCACAGCTT-3', $81 \mathrm{bp})$, ActR IB (5'-TACTCTGTGTCTGGCAGGCTACTC-3' and 5'-GCTTTGGTTCCACAGTCTGAGAT-3', 82 bp), ActR IIA (5'-CCTGTTTTAAGAGATTATTGGCAGAA-3' and 5'-TGCGTCGTGATCCCAACAT-3', 84 bp), ActR IIB (5'-TTCGATTTGAGCCAGGGAAA-3' and 5'-GAGCAC CTCAGGAGCCATGT-3', 80 bp), and $\beta$-actin (5'-GCGAGA AGATGACCCAGATC-3', 5'-GGATAGCACAGCCTGGAT AG-3'; 77 bp). qPCR was performed on the StepOneplus Real-Time PCR system using Power SYBR-Green PCR Master Mix (Applied Biosystems; Thermo Fisher Scientific, Inc.). PCR was performed with $1 \mu \mathrm{l}$ of cDNA in $20 \mu \mathrm{l}$ reaction mixtures, consisting of $10 \mu \mathrm{l}$ of Power SYBR-Green PCR Master Mix, $2 \mu 1$ of primers, and $7 \mu \mathrm{l}$ of PCR-grade water. The reactions were performed with a denaturation step at $95^{\circ} \mathrm{C}$ for $10 \mathrm{~min}$, followed by $40 \mathrm{cycles}$ of $95^{\circ} \mathrm{C}$ for $15 \mathrm{sec}$ and $60^{\circ} \mathrm{C}$ for $1 \mathrm{~min}$. The relationship between a target gene and $\beta$-actin was determined using the formula $2^{\text {-(target gene }-\beta \text {-actin) }}$, and the relative quantities of transcripts were measured.

Immunoblot analysis. Cells were collected, washed with cold phosphate-buffered saline, and then treated with lysis buffer containing $1 \mathrm{mM}$ PMSF (Cell Signaling Technology, Inc.). Protein concentrations were determined using BCA protein assays (Thermo Fisher Scientific, Inc.) according to the manufacturer's protocol. Ten micrograms of protein were fractionated on 10 or $12 \%$ sodium dodecyl sulfate polyacrylamide gel electrophoresis gels and transferred onto a nitrocellulose membrane (Amersham Pharmacia Biotech). The membranes were blocked with $1 \%$ bovine serum albumin (BSA) for $1 \mathrm{~h}$ at room temperature and then incubated overnight at $4^{\circ} \mathrm{C}$ with antibodies against Smad2, phosph-Smad2, Smad3, phosphor-Smad3, Smad4 (Cell Signaling Technology, Inc.), Smad7 (Santa Cruz Biotechnology, Inc.), and $\beta$-actin (Sigma-Aldrich; Merck KGaA). The antibodies were diluted (1:1,000 for Smad2, 3 and 4; 1:250 for Smad7; 1:5,000 for $\beta$-actin) using Tris-buffered saline containing $0.05 \%$ Tween-20 (TBS-T). After washing with TBS-T for $1 \mathrm{~h}$, the membranes were incubated for $1 \mathrm{~h}$ at room temperature with anti-rabbit and anti-mouse horseradish peroxidase-conjugated secondary antibodies diluted 1:3,000 (1:10,000 for $\beta$-actin) in TBS-T. The membranes were subsequently washed with TBS-T for $1 \mathrm{~h}$, and proteins were detected using Amersham ECL Prime Western Blotting Detection Reagent (GE Healthcare Life Sciences). Protein expression was analyzed using an Amersham Imager 600 (GE Healthcare Life Sciences). Protein band densities were measured using ImageJ analysis software (ImageJ, version 1.44; National Institutes of Health).

Statistical analysis. Data are expressed as the mean \pm standard error. Data were compared by one-way analysis of variance and Tukey's post hoc test. Statistical analyses were performed using the GraphPad Prism 5 software (GraphPad Software Inc.). $\mathrm{P}<0.05$ and $\mathrm{P}<0.01$ were considered to indicate statistical significance.

\section{Results}

Regulation of activin, follistatin and ActR mRNA with increasing passages. Cells were cultured 5-15 passages in vitro, and expression of activin signal gene mRNA was measured by qPCR. The activin A and follistatin transcripts were significantly enhanced with increasing passage number (Fig. 1A). The ActR IB mRNA level was increased at passage 10 compared to passage 5 but then decreased at passage 15 . The ActR IA, IIA and IIB transcripts were significantly reduced with increasing passage number (Fig. 1B).

Regulation of Smad signaling protein with increasing passages. To determine a potential role of Smad signaling in normal human dermal fibroblasts, cells were cultured 5-15 passages in vitro, and expression of Smad signal genes protein was measured by immunoblot analysis. The phosphorylation of Smad2 and 3 proteins was significantly decreased with increasing passage number, and the level of Smad4 protein was reduced. The Smad7 of Smad inhibitor was enhanced with increasing passages number (Fig. 2A and B).

\section{Discussion}

Skin aging involves a variety of processes that are influenced by physiological phenomena from chronologic or natural aging, as well as environmental factors of photoaging (11). Activin, its receptors, and follistatin (activin binding proteins) are important regulators of cell proliferation, differentiation and apoptosis in hair follicle initiation, hair cycling, normal skin homeostasis, and wound healing (3). Activins are involved in wound repair through regulation of skin and immune cell migration and differentiation, as well as re-epithelialization and formation of granulation tissue. Activins also affect the expression of collagens through fibroblasts and modulate scar formation (12). We found that the activin A and follistatin transcripts were significantly increased with increasing passage number. These results suggest that activin A and follistatin signals are enhanced in aging fibroblasts during senescence. Activins have shown an important role in wound repair as well as in keratinocyte differentiation, in dermal fibrosis, and possibly also in human skin disease (13). An increase in the 
A

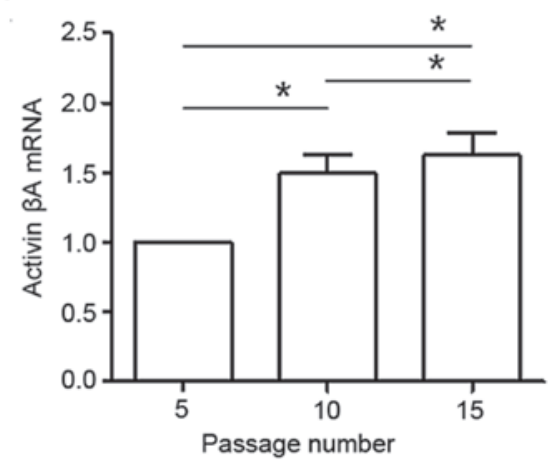

B
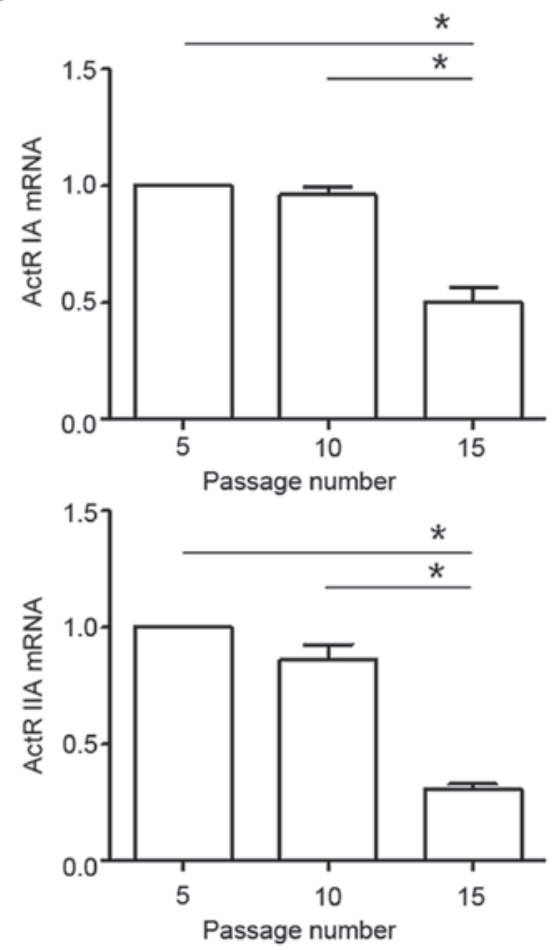
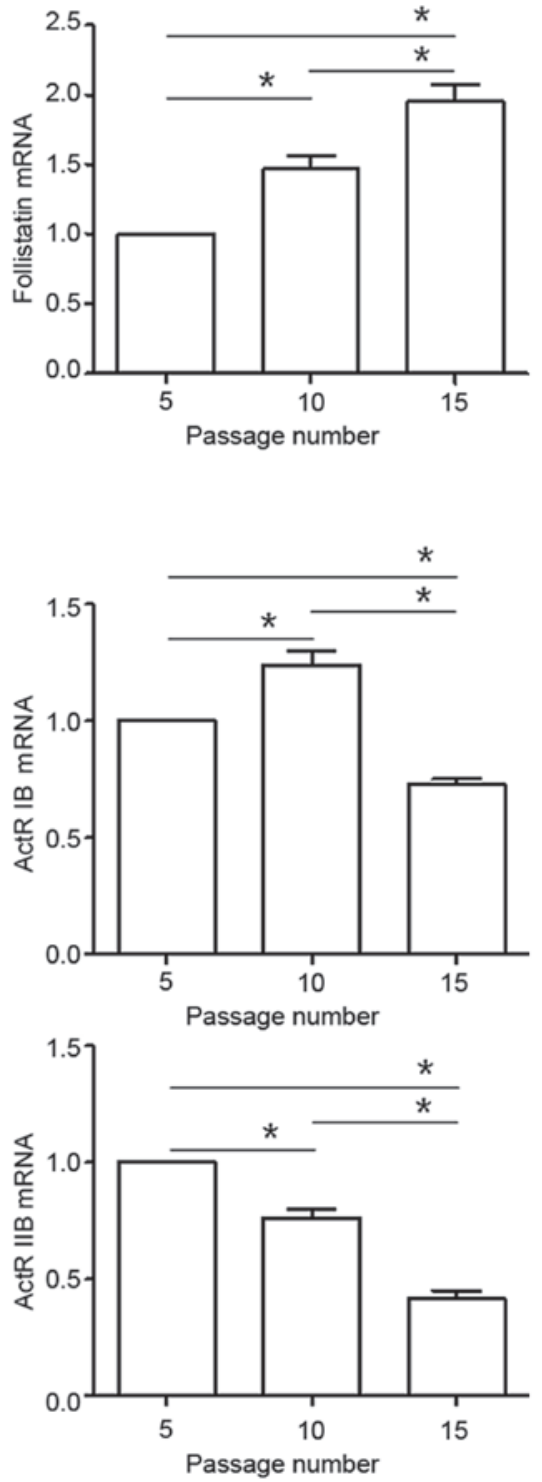

Figure 1. Expression of activin, follistatin, and ActR mRNA in normal human dermal fibroblasts. Cells were incubated from passage numbers 5 to 15 . Expression of mRNA was measured using qPCR. The relationships between (A) activin and follistatin, and (B) ActR and $\beta$-actin were determined using the formula, $2^{\text {-(target gene - } \beta \text {-actin) }}$, and the relative quantities of transcripts were measured. The data are mean \pm SD of two independent sets of triplicate samples. ${ }^{*} \mathrm{P}<0.05$, compared with 5 passages. ActR, activin receptors.

level of activin A mRNA in human basal cell carcinomas and squamous cell carcinomas was noted compared with normal skin, whereas the level of follistatin mRNA was similar in normal and tumorigenic skin (14). Activin and follistatin are an important regulatory system modulating developmental and regeneration processes (15). Activin A and follistatin are produced by normal and abnormal hepatocytes and help regulate hepatocyte regeneration in the healthy liver. Pathological increase of both activin and follistatin in hepatocyte is shown with several liver diseases including fibrosis, cirrhosis, and hepatocellular carcinoma (16). Activin A has shown an increase in serum from older women (43-47 years old) relative to younger women (19-38 years old) $(17,18)$. The expression of follistatin is altered in the tissue during fibrosis, suggesting a role of endogenous follistatin in regulating the fibrotic effect of activin (19). We could not perform ELISA of activin A and follistatin using supernatant. This is because cells must be cultured for several periods of time, so after 3 days of incubation, the medium must be exchanged with a new medium and as the number of passages increases, the growth rate of the cells is delayed and incubation time is not constant. In addition each time the medium was exchanged to maintain cell growth, various factors were lost from the supernatant and new materials were created. The signal transduction pathway is highly conserved for the TGF- $\beta$ superfamily members, involving the receptor-Smad system. Similar to TGF- $\beta$, bone morphogenic protein (BMP), and activin needs two type of the cell surface receptors (Type I and II receptor) for its signal transduction (20). However, the mechanisms through which activin signaling pathways cause aging in dermal fibroblasts are not well understood. In this study, we used passaged fibroblasts as a model for skin aging, focusing on the signal pathway as the cause of intrinsic senescence. We found that ActR IA, IB, IIA and IIB transcript levels were all reduced in late-passage 
A

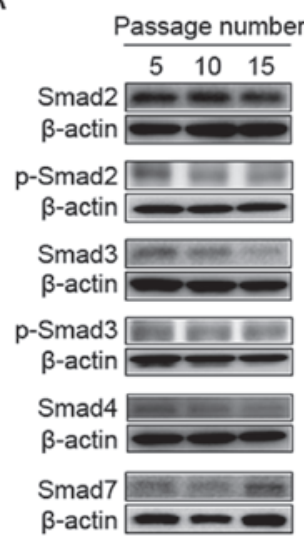

B
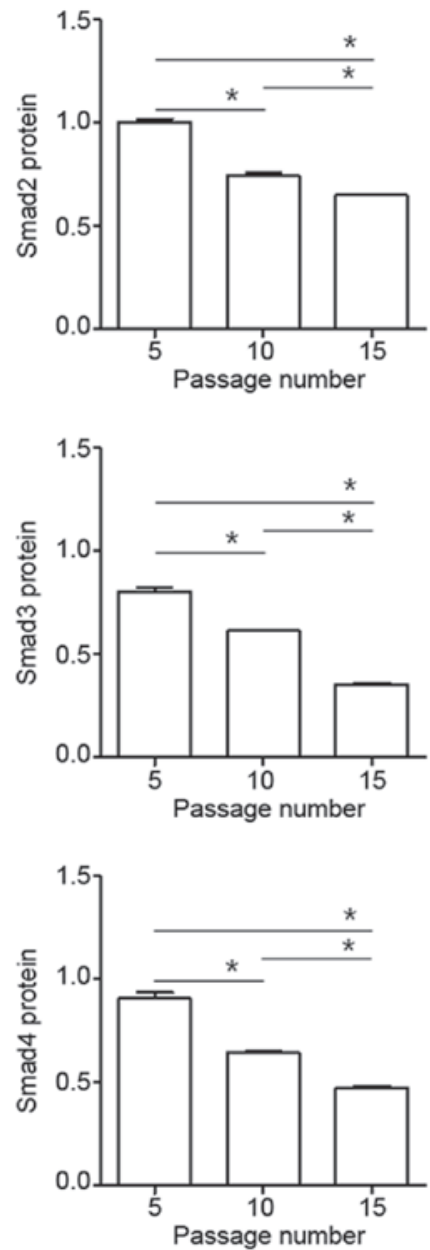
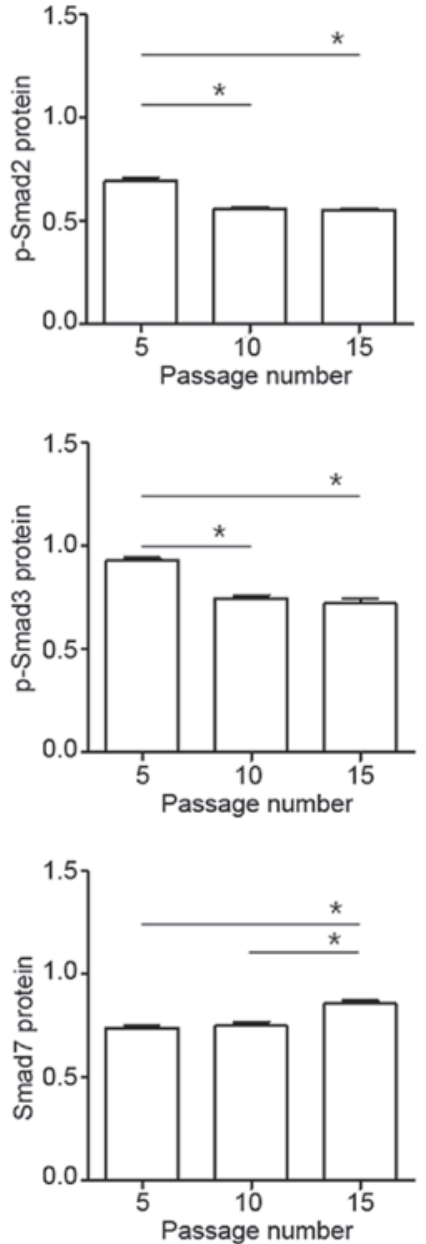

Figure 2. Expression of Smad proteins in normal human dermal fibroblasts. Cells were incubated from passage numbers 5 to 15 . Protein expression was determined using immunoblot analysis. (A) Cells were lysed, and $10 \mu \mathrm{g}$ of soluble protein was separated by electrophoresis on a $10 \%$ SDS-PAGE gel. (B) Densitometry analyses are presented as the relative ratio of Smad to $\beta$-actin. The data are mean \pm SD of two independent sets of triplicate samples. ${ }^{*}<0.05$, compared with 5 passages.

fibroblasts. These results showed that passaged human fibroblasts undergo decreased ActR I and II transcription during replicative senesces, suggesting repressed in aging fibroblasts as a results of downregulated ActR binding capacity. When human skin ages, decreases in the size and rigidity of fibroblasts enhance TGF- $\beta$ receptor type II (TGF $\beta$ RII) mRNA and protein levels. TGF $\beta$ RII promoter activity is also decreased, suggesting that downregulation of TGF $\beta$ RII expression may result, at least in part, from reduced gene transcription (21). Aging rat prostate showed significantly decreased TGF $\beta$ RI and TGF $\beta R I I$ mRNA in older rat tissue recombinants compared with 4-, 12- and 17-month-old recombinant tissues. In contrast, normal rat prostates of different age groups showed no effect on the levels of TGFßRI and TGFßRII mRNA (22). The levels of TGFßRII mRNA and protein in the epidermis of the forearm (sun-exposed) of the elderly were significantly lower than those of upper-inner arm (sun-protected) skin of the same individual (23). Activin and its receptor are expressed primarily in mouse skin and are primarily localized to fibroblasts, and increased expression of activin $\beta$-subunits in the skin after injury suggests a role in skin repair (24).

Smads constitute a structurally similar family of proteins that are key signal transducers for receptors in the TGF- $\beta$ superfamily and are critical for regulation of cell development and growth (25). Phosphorylated Smad2 and Smad3 associated with Smad4 induce signal transduction generated by TGF- $\beta$ and activin, while Smad7 inhibits this intracellular signaling (26). We did find significant decrease in Smad2, 3 and 4 protein levels with increasing passage number, and phosphorylation of Smad 2 and 3 was reduced. However, Smad 7 was increased at late-passage number. These results suggest that Smad genes suppress signaling activity during replicative senescence in normal human dermal fibroblasts, and that Smad7 acts as feedback regulation of the activin signaling pathway. Smads signaling is repressed in aging fibroblasts as a result of decreased ActR binding capacity. Taken together, these results indicate that expression of ActR is decreased, and Smad binding force are reduced. However, inactivation of Smad2 and Smad3 phosphorylation decreased binding of Smad4, Therefore, it affects the acitivn/Smad signaling in replication senescence. The immunoreactivity of $\mathrm{pSmad} 2$ was observed to decrease in the epidermis of photoaged forearm skin versus matched intrinsically aged skin. This decrease was also found in the epidermis of upper-inner arm skin of the elderly versus the young. The UV-induced downregulation of TGFßRII and the concerted over-expression of Smad7 
cause inhibition of the TGF- $\beta$-induced phosphorylation of Smad2 (23). In thyroid cells, the expression of Smad and the presence of $\mathrm{pSmad} 2 / 3$ and Smad4 proteins in the nucleus of tumor cells indicate propagation of TGF- $\beta$ /activin signaling. However, high expression of Smad7 in most malignant tumors may contribute to reduction of Smad antiproliferative signaling in thyroid carcinomas (27). Overexpression of Smad7 blocked TGF- $\beta 1$-induced Smad3 phosphorylation and nuclear accumulation of $\mathrm{Smad} 2 / 3$ in fibroblasts derived from human Peyronie's disease (28). Recently we have demonstrated that the TGF- $\beta$ signaling pathway is controlled primarily by downregulation of receptors at the transcriptional level, and suppression of the TGF- $\beta /$ Smad pathway is associated with reduced MMP, TIMP, and collagen type I and III expression in aging human dermal fibroblasts, suggesting that activation of NF- $\mathrm{B}$, Akt-JNK and MAPK reduce $\mathrm{TGF}-\beta / \mathrm{Smad}$ transcription in passaged normal human dermal fibroblasts (29). We assumed that decrease of TGF- $\beta$ /activin/Smad pathways in aging human dermal fibroblasts is reduced receptor binding capacity as well as activity of Smad phosphorylation. Moreover, aging of fibroblasts exerted downregulation of expression effects on target gene by decreasing TGF- $\beta$ /Activin/Smad signal pathway.

In conclusion, we demonstrated that increasing passage number in normal human dermal fibroblasts enhanced activin $\mathrm{A}$ and follistatin, whereas activin signaling pathway is controlled primarily through downregulation of ActR at the transcriptional level, and suppressed the expression of Smad signaling.

\section{Acknowledgements}

Not applicable.

\section{Funding}

This research was supported by Basic Science Research Program through the National Research Foundation of Korea (NRF) funded by the Ministry of Education (NRF-2017R1D1A1B03027993).

\section{Availability of data and materials}

The datasets used and/or analyzed during the current study are available from the corresponding author on reasonable request.

\section{Authors' contributions}

YIK performed most of the experiments, analyzed data and wrote the manuscript. MKS contributed to the study concept and design of the project. CL analyzed the data. All authors have read and approved the final version of the manuscript.

\section{Ethics approval and consent to participate}

Not applicable.

\section{Patient consent for publication}

Not applicable.

\section{Competing interests}

The authors declare that they have no competing interests.

\section{References}

1. DePaolo LV, Bicsak TA, Erickson GF, Shimasaki S and Ling N: Follistatin and activin: A potential intrinsic regulatory system within diverse tissues. Proc Soc Exp Biol Med 198: 500-512, 1991.

2. Xia Y and Schneyer AL: The biology of activin: Recent advances in structure, regulation and function. J Endocrinol 202: 1-12, 2009.

3. McDowall M, Edwards NM, Jahoda CA and Hynd PI: The role of activins and follistatins in skin and hair follicle development and function. Cytokine Growth Factor Rev 19: 415-426, 2008.

4. Kawakami S, Fujii Y and Winters SJ: Follistatin production by skin fibroblasts and its regulation by dexamethasone. Mol Cell Endocrinol 172: 157-167, 2001.

5. Attisano L, Wrana JL, Montalvo E and Massagué J: Activation of signalling by the activin receptor complex. Mol Cell Biol 16: 1066-1073, 1996

6. Moustakas A, Souchelnytskyi S and Heldin CH: Smad regulation in TGF- $\beta$ signal transduction. J Cell Sci 114: 4359-4369, 2001

7. Nakao A, Afrakhte M, Morén A, Nakayama T, Christian JL, Heuchel R, Itoh S, Kawabata M, Heldin NE, Heldin CH, et al: Identification of Smad7, a TGFbeta-inducible antagonist of TGF-beta signalling. Nature 389: 631-635, 1997.

8. Afrakhte M, Morén A, Jossan S, Itoh S, Sampath K, Westermark B, Heldin $\mathrm{CH}$, Heldin NE and ten Dijke P: Induction of inhibitory Smad6 and Smad7 mRNA by TGF- $\beta$ family members. Biochem Biophys Res Commun 249: 505-511, 1998.

9. Kim KS, Park HK, Lee JW, Kim YI and Shin MK: Investigate correlation between mechanical property and aging biomarker in passaged human dermal fibroblasts. Microsc Res Tech 78: 277-282, 2015

10. Kuchler RJ: Development of animal cell populations in vitro. In: Biochemical Methods in Cell Culture and Virology. Kuchler RJ (ed). Dowden, Hutchinson \& Ross, Inc., Stroudsburg, PA, pp90-113, 1977.

11. Sjerobabski-Masnec I and Situm M: Skin aging. Acta Clin Croat 49: 515-518, 2010.

12. Moura J, da Silva L, Cruz MT and Carvalho E: Molecular and cellular mechanisms of bone morphogenetic proteins and activins in the skin: Potential benefits for wound healing. Arch Dermatol Res 305: 557-569, 2013.

13. Beer HD, Gassmann MG, Munz B, Steiling H, Engelhardt F, Bleuel $\mathrm{K}$ and Werner S: Expression and function of keratinocyte growth factor and activin in skin morphogenesis and cutaneous wound repair. J Investig Dermatol Symp Proc 5: 34-39, 2000.

14. Antsiferova M, Huber M, Meyer M, Piwko-Czuchra A Ramadan T, MacLeod AS, Havran WL, Dummer R, Hohl D and Werner S: Activin enhances skin tumourigenesis and malignant progression by inducing a pro-tumourigenic immune cell response. Nat Commun 2: 576, 2011.

15. Kojima I, Maeshima A and Zhang YQ: Role of the activin-follistatin system in the morphogenesis and regeneration of the renal tubules. Mol Cell Endocrinol 180: 179-182, 2001

16. Refaat B, Ashshi AM, El-Shemi AG and Azhar E: Activins and Follistatin in Chronic Hepatitis $\mathrm{C}$ and Its Treatment with Pegylated-Interferon- $\alpha$ Based Therapy. Mediators Inflamm 2015: $287640,2015$.

17. Santoro N, Adel T and Skurnick JH: Decreased inhibin tone and increased activin A secretion characterize reproductive aging in women. Fertil Steril 71: 658-662, 1999.

18. Barrios-Silva LV, Parnell M, Shinwari ZB, Chaudhary GA, Xenofontos T, van Bekhoven A, McArthur S and Elliott BT: Activin subfamily peptides predict chronological age in humans. Physiol Rep 6: e13823, 2018.

19. Hedger MP and de Kretser DM: The activins and their binding protein, follistatin-Diagnostic and therapeutic targets in inflammatory disease and fibrosis. Cytokine Growth Factor Rev 24: 285-295, 2013.

20. Massagué J: TGF- $\beta$ signal transduction. Annu Rev Biochem 67: 753-791, 1998.

21. Fisher GJ, Shao Y, He T, Qin Z, Perry D, Voorhees JJ and Quan T: Reduction of fibroblast size/mechanical force down-regulates TGF- $\beta$ type II receptor: Implications for human skin aging. Aging Cell 15: 67-76, 2016. 
22. Zhao H, Patra A, Tanaka Y, Li LC and Dahiya R: Transforming growth factor- $\beta(\mathrm{s})$ and their receptors in aging rat prostate. Biochem Biophys Res Commun 294: 464-469, 2002.

23. Han KH, Choi HR, Won CH, Chung JH, Cho KH, Eun HC and Kim KH: Alteration of the TGF- $/$ /SMAD pathway in intrinsically and UV-induced skin aging. Mech Ageing Dev 126: 560-567, 2005.

24. Hübner G, Hu Q, Smola H and Werner S: Strong induction of activin expression after injury suggests an important role of activin in wound repair. Dev Biol 173: 490-498, 1996.

25. Hata A and Chen YG: TGF- $\beta$ Signaling from Receptors to Smads. Cold Spring Harb Perspect Biol 8: a022061, 2016.

26. Massagué J, Seoane J and Wotton D: Smad transcription factors. Genes Dev 19: 2783-2810, 2005.
27. Matsuo SE, Fiore AP, Siguematu SM, Ebina KN, Friguglietti CU, Ferro MC, Kulcsar MA and Kimura ET: Expression of SMAD proteins, TGF-beta/activin signaling mediators, in human thyroid tissues. Arq Bras Endocrinol Metabol 54: 406-412, 2010.

28. Choi MJ, Song KM, Park JM, Kwon MH, Kwon KD, Park SH, Ryu DS, Ryu JK and Suh JK: Effect of SMAD7 gene overexpression on TGF- $\beta 1$-induced profibrotic responses in fibroblasts derived from Peyronie's plaque. Asian J Androl 17: 487-492, 2015.

29. Kim YI, Kim KS, Ahn HJ, Kang IH and Shin MK: Reduced matrix metalloproteinase and collagen transcription mediated by the TGF- $\beta /$ Smad pathway in passaged normal human dermal fibroblasts. J Cosmet Dermatol: Sep 11, 2019 (Epub ahead of print). 